\title{
ON THE INFLUENCE OF BANKING RELATIONSHIPS ON FRENCH SMES FAILURE
}

\author{
David Veganzones \\ ESCE International Business School - Paris \\ dveganzones@esce.fr \\ Eric Séverin \\ University of Lille- Lille \\ eric.severin@univ-lille.fr
}

\begin{abstract}
Small and medium firms are highly dependent on banks to finance their business activities. Thus, banking relationship may be crucial to overcome financial difficulties and to ensure their continuity. Accordingly, this paper investigates the influence of banking relationship on SMEs failure. In particular, four measures that firms can control to build their banking relationships and, that resemble standard variables from the literature on bank/firms relationships are evaluated: the breadth of relationships (number of banks), the relationship length(relationship duration), the relationship proximity (bank-firm distance) and, the relationship form (type of bank). Applying a logistic regression to a unique sample of 4960 French SME firms over the period 2013-2016, we evidence that banking relationships have a significant role on the SMEs likelihood of failure. More precisely, we find that multibank relationships, working with a small bank and relationship length are significantly negative correlated with SMEs failure. The opposite effect appears in bank-firm distance, which increases the SMEs probability of failure. Additionally, a corporate failure prediction model was built based on both financial ratios and banking relationship variables. The performance of this model was compared to a model based solely on financial ratios as predictive indicators. The results indicate that banking relationship variables possess prediction power to failure and enhance the performance of corporate failure models. Consequently, our findings are important from a policy perspective to further comprehend the role that banks play on SMEs failure.
\end{abstract}

Keywords: Banking Relationship, Corporate Failure Prediction, Finance

JEL classification: G21, G23, L26

\section{INTRODUCTION}

In today's economic environment, the number and magnitude of bankruptcy procedures are increasing considerably. In this regard, whether firms receive sufficient support from their correspondent banks and financial institutions has become a key factor to overcome their critical financial difficulties and to ensure business continuity (Franco and Haase, 2010). This fact is notably more crucial for small and medium-sized enterprises (SMEs) due to they do not usually have access to organized capital markets; banks represent the main source of external financing. Indeed, SMEs reported that access to finance is an elemental assistance for their activities and growth (Carbo-Valverde et al., 2016). Thus, bank involvement with SMEs is significant everywhere in the world. Nonetheless, one may call into question whether banking relationships might influence SMEs failure risk, as SMEs business activities and performance are strongly dependent on banking financing. This is the reason why this paper explores the role that banking relationship plays in SMEs likelihood of failure.

\section{BACKGROUND}

Boot (2000) defined banking relationships as "the provision of financial services by a financial intermediary that invests in obtaining customer-specific information, often relevant and private in nature, and evaluates the profitability of these types of investments through multiple interactions with the same customer over time and/or across products". In this regard, banks and firms 
must develop trustworthy relationships based on the exchange of specific information that is only available for them, which might lead to fruitful relationships for both counterparts. Nonetheless, these relationships may be also detrimental, especially for firms in close banking relationships. In this case, studies suggest that banks might appropriate the unique information provided by firms and that is not available to other organizations, which may lead to firms becoming captives of their financial intermediary (Von Thadden, 2004). Banking relationships thus might lead to favorable or detrimental effects and consequences. Our study is of significant importance to clarify the effects of those characteristics on the SMEs exposure to failure.

In this regard, Degryse et al. (2009), in line with Agarwal et al. (2018), specify four measures that firms can control to build their banking relationships and, that resemble standard variables from the literature on bank/firms relationships: the breadth of relationships (number of banks), the relationship length (relationship duration), the relationship proximity (bank-firm distance), the relationship form (type of bank). The discussion on the breadth of relationships has been historically the main focus of empirical studies, analyzing firms' number of bank relationships that serve as an indicator for the presence of relationship lending. From Carletti (2004) theoretical paper, maintaining a single relationship firms strengthen the link with their lender. Therefore, it is the optimal mechanism to channel loan from bank to firms because it minimizes monitoring costs. This is based on the premise that maintaining an exclusive bank relationship promotes the development of close ties between bank and borrower (Elsas, 2005). Relationship length reflects the intensity of banking relationship over time. In general, a longer relationship creates incentive for a firm to share exclusive information, which encourages the willingness of a bank to increase financing resources to a firm because it can be easily screened and monitored. Indeed, the literature predicts a positive effects of length for firms financing because strengthen their bank relationships is essential in raising firms' ability to borrow (Bartoli et al., 2014). As small bank use more subjective processes, they are capable of transmitting and quantifying the information of opaque SMEs to engage on a banking relationship (Stein, 2002). In addition, small banks may have a comparative advantage in verifying that information because they are closer to their borrowers in local markets (Agarwal and Hauswald, 2006). Thus, the capacity of different type of banks in quantifying and transmitting through its communication channels the information gathered from opaque SMEs might influence their willingness to supply financing. Finally, bank-firm distance concerns the ability to collect and use private information in banking relationship, which might explain the availability and pricing of bank loans. Thus, the expected effects on firms financing held by a firm depend on the geographic extend (Neuberger and Räthke, 2009). In sum, these variables determine the factors to establish banking relationships and, empirical studies on banking relationships to SMEs have been often relied on those measures to investigate their positive/negative consequences for firms.

\section{DATA}

We gathered the data over two periods of time (2013-2014; 2015-2016) from Diane database managed by bureau Van Dijk, which provides information for French Firms. The dataset then was built through the following stages. Firstly, we identify French SMEs firms according to European Commission criteria that went bankrupt, that is, those proceeded to be liquated or reorganized in the period studied. Secondly, we collect those samples that provide information about banking relationships, from which annual accounts and income statements as well as firms' bank information were extracted. Finally, we collect the additional information required about banks-firm relationships using Altares dataset managed by Insead OEE Data Services (IODS). There were 2480 failed SMEs in this position. Moreover, in line with Ciampi (2015), non-failed firms were randomly selected, by a paired-match technique to obtain the same proportion and characteristics of failed firms. Thus, our final dataset is composed of 4960 samples, which includes the same number of failed and non-failed firms. The fact that samples 
from two periods present different characteristics allows evaluating the robustness in two independent datasets.

\subsection{Banking relationship variables}

Four characteristics have been considered: number of banks, type of bank, relationship length, and bank-firm distance. The "number of banks" is a dummy variable that takes a value 1 if a firm has multibank relationships and 0 in the case that it works with a single bank (Bartoli et al., 2014). The variable "type of bank" has a value 1 for a small bank and 0 for a big bank (Höwer, 2016). The "bank-firm distance" variable considers the physical distance that separates firms from their main bank. More precisely, it is the logarithm transformation of the kilometers distance between a firm and its main bank (Neuberger and Räthke, 2009). Finally, the variable "relationship length" has a value of 1 is a firm works with the same main bank over the period study and 0 otherwise.

\subsection{Control variables}

Financial ratios represent the primary explanatory variable to predict corporate failure. That is why they have been included in our model. From the gathered annuals accounts and financial statements, we have computed 50 financial ratios. The stepwise method was applied to select the most relevant variables. In this regard, five variables were selected, which represent all financial dimensions. In line with expectations, failed firms present lower liquidity and profitability values (current liabilities / total assets; quick assets / total assets; EBITDA / Permanent equity) as well as a weaker financial structure (value added / fixed assets; NOWC / total sales) in comparison to non-failed firms

Moreover, a set of variables is also computed to control for other factors related to banking relationships that may play a role on SMEs likelihood of failure. Coverage and financial demands are introduced because it measures the capacity of a firm to fulfill its financial obligation and the financial requirement, which might effect on SMEs failure. Besides, firm size, measured as the natural algorithm of total assets, is also included as banking relationships and then, the likelihood of failure may be affected by firm dimension.

\section{EMPIRICAL EVALUATION}

The literature offers a diverse and extensive amount of methods to design corporate failure models. Recently, a vast amount of studies have been designed based on artificial intelligence techniques because they do not require any specific assumption, that is, they learn directly from the data which makes them more reliable and, the reliance on nonlinear approaches offers extended possibilities for testing complex data (Kumar and Ravi, 2007). However, even if these techniques present such advantages, they are often criticized because the determination of parameters associated with the classifier is not straightforward and, they are a black-box for the decision makers, preventing any type of interpretability. Thus, in the context of our study, the impossibility of analyzing the estimated coefficient is a major inconvenient that prevent to evaluate the effect of banking relationship variables on SMEs probability of failure and its prediction power.

Consequently, as the purpose of this study is to explore the role of bank relationships on predicting SMEs failure, we used a method, logistic regression, which is widely employed in corporate failure. Indeed, the fact that logistic regression method provides estimated coefficients and their significance can be separately interpreted makes possible to explore our research objective. Besides, the selection of this method over commonly used discriminant analysis is due to logistic regression requires fewer statistical condition to be optimal. This method is based on well-known concepts from statistical decision and on analyzing, summarizing and interpreting data. 
Table 1: Coefficients and classification results

\begin{tabular}{|c|c|c|c|c|c|c|}
\hline \multirow[b]{3}{*}{ Intercept } & \multicolumn{2}{|c|}{ 2013-2014 period } & \multicolumn{2}{|c|}{ 2015-2016 period } & \multicolumn{2}{|c|}{ Entire data (2013-2016) } \\
\hline & Model A & Model B & Model A & Model B & Model A & Model B \\
\hline & $-0.653 * *$ & $-0.803 * *$ & $-0.451 * *$ & $-0.705 * *$ & $-0.516^{* *}$ & $-0.743 * *$ \\
\hline \multicolumn{7}{|l|}{ Explanatory variables } \\
\hline $\mathrm{N}^{\circ}$ banks & & $-0.473 * *$ & & $-0.478 * *$ & & $-0.457 * *$ \\
\hline Type of bank & & $-0.350 * *$ & & $-0.313 * *$ & & $-0.379 * *$ \\
\hline Relationship length & & $-0.147^{*}$ & & $-0.235^{*}$ & & $-0.176^{*}$ \\
\hline Bank-firm distance & & $0.367 * *$ & & $0.423 * *$ & & $0.393 * *$ \\
\hline \multicolumn{7}{|l|}{ Control variables } \\
\hline Current liabilities/ Total assets & $1.064 * *$ & $1.123 * *$ & $0.987 * *$ & $1.068 * *$ & $1.052 * *$ & $0.997 * *$ \\
\hline Quick assets / Total assets & $-1.109^{* *}$ & $-1.121 * *$ & $-1.086^{* *}$ & $-1.233 * *$ & $-1.014^{* *}$ & $-1.118 * *$ \\
\hline EBITDA / Permanent Equity & $-0.519 * *$ & $-0.439 * *$ & $-0.553 * *$ & $-0.492 * *$ & $-0.498 * *$ & $-0.451 * *$ \\
\hline Value added / Fixed assets & $-0.615^{* *}$ & $-0.613 * *$ & $-0.475 * *$ & $-0.326 * *$ & $0.512 * *$ & $-0.444 * *$ \\
\hline N.O.W.C / Total sales & $-1.355^{* *}$ & $-1.550 * *$ & $-0.741 * *$ & $-0.649 * *$ & $-1.135^{* *}$ & $-0.938 * *$ \\
\hline Coverage & & $-0.115^{*}$ & & $-0.197 *$ & & $-0.190 *$ \\
\hline Financial needs & & -0.001 & & 0.091 & & 0.080 \\
\hline Firms size & & -0.093 & & -0.069 & & -0.049 \\
\hline Industry dummies & Yes & Yes & Yes & Yes & Yes & Yes \\
\hline R-squared & 0.513 & 0.565 & 0.598 & 0.634 & 0.537 & 0.584 \\
\hline Observations & 2538 & 2538 & 1926 & 1926 & 4464 & 4464 \\
\hline Accuracy (correctly classified firms) (\%) & 73.1 & $76.6^{*}$ & 77.7 & $81.1^{*}$ & 73.3 & $77.5^{*}$ \\
\hline Correct classified bankrupt firms (\%) & 71.3 & $75.8 * *$ & 74.9 & $79.5^{* *}$ & 71.0 & $77.0 * *$ \\
\hline Correct classified healthy firms (\%) & 74.9 & 77.4 & 80.6 & 82.6 & 75.6 & 78.0 \\
\hline Observation & 282 & 282 & 214 & 214 & 496 & 496 \\
\hline
\end{tabular}

\subsection{Results}

The estimated results indicate that all banking relationship characteristics present significant coefficients, evidencing that these explanatory variables play a role in SMEs likelihood of failure. It is important to remark that we interpret our result cautiously but, as causal relation between banking relationship characteristics and SMEs performance and failure. In this context, a firm having multibank relationships is less likely to fail, which confirms H1. This is an important result of this study and for the existing literature because it enlightens the controversy about the number of banking relationship effects. This finding corroborates the Detragiache et al. (2000) study that support the beneficial gains that SMEs can profit from multibank relationships, in which is more likely to obtain liquidity and avoid the risk of failure. Besides, the diverse options to finance access will finally result in less financial constrain and better term conditions for firms because it gives more flexibility. One may consider that a multibank relationship could provide a "funding oxygen pump" because of having this relationship increases the chance of finding a creditor ready to grant financing. This fact may be especially relevant if a SME suffer financial distress because the additional funding that it can be acquired from one of its bank relationships can avoid the implications that this circumstance can cause on its performance, that is, several negative aspect that might lead to an involvement on a bankruptcy procedure. Indeed, Fuss and Vermuelen (2008) corroborate that a SME can obtain extra credit in the case of adverse shock working with multiple banks.

Furthermore, a SME that works with a small bank is negative correlated with the probability of failure. It then attests the general concept that SME-small bank relationship is fruitful for both parts and, especially to tailor the firm necessities. Indeed, it is not entirely odd to think that the decentralized organization of small banks, which is crucial for manage the information provided by SMEs (Stein, 2002), makes it possible that SMEs can receive personalized financial services and products adapted to their industry sector and business. Thus, it enables that SMEs might possess adequate source of financing and resources to develop their projects and investments that encourage their competiveness and performance. As a result, the SMEsmall bank relationship facilitates the firm survival.

In line with the literature, longer banking relationships is beneficial for SMEs as it is negative correlated with their probability of failure. The trustworthy relationships encourage firms to 
transmit data and, to banks to better monitor and serve firms. As a consequence, SME should obtain an increased availability of debt at lower cost (Berger et al., 2001), which favors the development of its operation and reduces the risk of being default. Moreover, because of community-based contact that a banking relationship represents, the closeness between a firm and its bank implies a major key element to ensure that the SME will be financially supported by the bank, which is crucial for its survival. In the case of SMEs, the closeness involves personalized and domestics contact to be more likely to transmit the prospect of their project and the viability of their business so that they can be financed and backed in the moment of distress. Indeed, this result and assentation are consistent with the literature that indicates that close relationships are linked with easier access to bank loans and SME profitability, fundamental elements for SMEs survival (Hasan et al., 2017). Thus, the increment on bankfirms distance is detrimental for the informational channel between both counterparts, especially for the quality and quantity of information received by bank. This result in making more risky and less efficiency for bank to serve firms, which lead to the worsening of firms financial condition and credits availability. Indeed, Agarwal and Hauswald (2006) evidenced that the probability of default on SMEs loans increases with the distance between borrowers and lenders. That may explain why bank-firm distance is found to be positive correlated with SMEs likelihood of failure. Finally, it is interesting to remark that banking relationship characteristics have certain prediction power to bankruptcy but, not that of financial ratios. Nonetheless, it is observed that those variables produce an improvement on failed firms, which is crucial in corporate failure prediction.

\section{CONCLUSION}

This paper resorts the role that banking relationship plays on French SMEs likelihood of failure. More precisely, we examine four characteristics that have been widely considering in the literature of banking relationships and that it is known that they might influence SMEs performance: number of banks relationships, type of bank, the duration of banking relationship, and bank-firm distance.

Our results indicate that banking relationships play an important role on the SMEs likelihood of failure. One may consider that this is the product of complete dependence of SMEs on banking financing to carry out their activities. Thus, governments should implement policies to facilitate favorable access to finance and to control for the uncompetitive conditions that banks may impose so that those SMEs with genuine potential could compete and grow, especially in the early stages. In this scenario, the number of SMEs that have to cease their activities due to the lack of financing could be reduced, lessening the role that banks play on SMEs failure, and creating a business-friendly environment to maintain a broad base of SMEs, which is crucial for the economic development and sustainability in industrialized countries. Unfortunately, our dataset is limited to three years of banking relationship, which make it impossible to establish the effects of more prolonged banking relationships. This could explain why the relationship length variable is less significant on SMEs failure, though it is mainly considered in banking relationship literature. That is why, the following further research will be considered to enhance the quality of this study. Firstly, collect larger data on banking relationship. Secondly, our results are based on the analysis of only one country, France, in which banks have a significant role in corporate finance, so more research is needed in order to generalize our results. Additionally, in this paper could only be considered banking relationships characteristics but, one may wonder whether credits terms (interest rates, repayment years, rate of late payments ...) might influence the SMEs failure as well as regional characteristics. Finally, acknowledging that failure is a dynamic process in which the initial condition of a firm changes over time until it fails, it would be interesting to contemplate the entire process of failure alongside with banking relationships. One could therefore investigate 
how this relationship impacts firm financial situation over time, from financial distress to bankruptcy.

\section{REFERENCES}

Agarwal, S., \& Hauswald, R. (2006). "Distance and information asymmetries in lending decisions". Washington DC, American University.

Agarwal, S., Chomsisengphet, S., Liu, C., Song, C., \& Souleles, N. S. (2018). "Benefits of relationship banking: Evidence from consumer credit markets". Journal of Monetary Economics, Vol. 96, pp.16-32.

Bartoli, F., Ferri, G., Murro, P., \& Rotondi, Z. (2014). "Bank support and export: evidence from small Italian firms”. Small Business Economics, Vol.42, No. 2, pp. 245-264.

Berger, A. N., Klapper, L. F., \& Udell, G. F. (2001). "The ability of banks to lend to informationally opaque small businesses". Journal of Banking \& Finance, Vol. 25, No. 12, pp. 2127-2167.

Boot, A. W. (2000). "Relationship banking: What do we know?". Journal of financial intermediation, Vol. 9, No. 1, pp. 7-25.

Carbo-Valverde, S., Rodríguez-Fernández, F., \& Udell, G. F. (2016). "Trade credit, the financial crisis, and SME access to finance". Journal of Money, Credit and Banking, Vol.48, No. 1, pp. 113-143.

Carletti, E. (2004). "The structure of bank relationships, endogenous monitoring, and loan rates". Journal of Financial Intermediation, Vol. 13, No.1, pp.58-86.

Ciampi, F. (2015). "Corporate governance characteristics and default prediction modeling for small enterprises. An empirical analysis of Italian firms". Journal of Business Research, Vol.68, No. 5, pp. 1012-1025.

Degryse, H., Kim, M., \& Ongena, S. (2009). "Microeconometrics of banking: methods, applications, and results". Oxford University Press, USA.

Detragiache, E., Garella, P., \& Guiso, L. (2000). "Multiple versus single banking relationships: Theory and evidence". The Journal of Finance, Vol. 55, No. 3, pp. 1133-1161.

Elsas, R. (2005). "Empirical determinants of relationship lending". Journal of Financial Intermediation, Vol. 14, No.1, pp. 32-57.

Franco, M., \& Haase, H. (2010). "Failure factors in small and medium-sized enterprises: qualitative study from an attributional perspective". International Entrepreneurship and Management Journal, Vol.6, No. 4, pp.503-521.

Fuss, C., \& Vermeulen, P. (2008). "The response of firms' investment and financing to adverse cash flow shocks: the role of bank relationships in Belgium". Review of Business and Economic Literature, Vol. 53, No. 1, pp. 5-34.

Hasan, I., Jackowicz, K., Kowalewski, O., \& Kozłowski, Ł. (2017). “Do local banking market structures matter for SME financing and performance? New evidence from an emerging economy". Journal of Banking \& Finance, Vol. 79, pp. 142-158.

Höwer, D. (2016). "The role of bank relationships when firms are financially distressed". Journal of Banking \& Finance, Vol. 65, pp. 59-75.

Kumar, P. R., \& Ravi, V. (2007). "Bankruptcy prediction in banks and firms via statistical and intelligent techniques-A review". European journal of operational research, Vol. 180, No. 1, pp. 1-28.

Neuberger, D., \& Räthke, S. (2009). "Microenterprises and multiple bank relationships: The case of professionals". Small Business Economics, Vol. 32, No. 2, pp. 207-229. 
Stein, J. C. (2002). "Information production and capital allocation: Decentralized versus hierarchical firms". The journal of finance, Vol. 57, No. 5, pp. 1891-1921.

Von Thadden, E. L. (2004). "Asymmetric information, bank lending and implicit contracts: the winner's curse". Finance Research Letters, Vol. 1, No. 1, pp. 11-23. 